https://nv.nltu.edu.ua

https://doi.org/10.15421/40280628

Article received 15.06.2018 p.

Article accepted 20.06.2018 p.

удк 004.942:519.632.4

$@ \bowtie$ Correspondence author

N. A. Andrushchak nandrush@gmail.com

Н. Б. Яворський, Н. А. Андрущак

Національний університет "Львівська політехніка", м. Львів, Україна

\title{
ЧИСЛОВИЙ МЕТОД ЗНАХОДЖЕННЯ ЕФЕКТИВНОГО ПОКАЗНИКА ЗАЛОМЛЕННЯ ПОРИСТИХ КОМПОЗИЦІЙНИХ МАТЕРІАЛІВ НА ОСНОВІ МІКРОРІВНЕВИХ МОДЕЛЕЙ
}

Розглянуто застосування розробленого числового методу знаходження ефективного показника заломлення для випадку пористих нанокомпозитів. На основі використання мікрорівневої коміркової моделі структури, методу генерування випадкових волокнистих включень 3 допомогою кривих Без'є та мікрорівневих коміркових моделей структури розвинено числовий метод знаходження ефективного показника заломлення пористих композитів, що дає змогу в рамках однотипної моделі розглядати складні структурні неоднорідності матеріалу та синтезувати відповідний показник заломлення на основі числового моделювання електростатичного поля. Така реалізація є простішою та потребує меншої кількості обчислень та ресурсів порівняно з аналогічними аналітичними методами. Завдяки регулярній структурі отриману мікрорівневу модель можна використовувати безпосередньо як скінченно-елементну дискретизацію, оскільки використання кривих Без'є дає змогу моделювати пори з урахуванням наноструктурних неоднорідностей. Запропонований метод було перевірено шляхом порівняння 3 наявними аналітичними моделями знаходження ефективного показника заломлення, такими як: Максвелла-Гарнета, моделлю Брюгемана та моделлю Друде (Сільберштейна). Спираючись на оцінку верхньої границі похибки апроксимації використаного методу скінченних елементів, отримані результати свідчать про більшу точність порівняно 3 аналітичною моделлю Друде (Сільберштейна).

Ключові слова: композиційні матеріали; мікрорівневі моделі; числове моделювання.

Вступ. Пористі композиційні матеріали, такі як анодований оксид алюмінію $\mathrm{Al}_{2} \mathrm{O}_{3}$, оксид кремнію $\mathrm{SiO}_{2}$, оксид титану $\mathrm{TiO}_{2}$ та інші, застосовують для створення мікросистем i сенсорів навколишнього середовища, фільтруючих елементів для мікро- i нанометрової фільтрації й поділу сумішей, матриць для синтезу наночастинок, наноелектронних приладів тощо. Це можливо завдяки наявності пористої фази з саморганізованим, зазвичай гексагональним розташуванням пор (Jaworski \& Andrushchak, 2017; Andrushchak, Jaworski \& Lobur, 2018; Jaworski \& Andrushchak, 2017; Jaworski et al., 2017).

Актуальною є задача знаходження ефективних фізичних характеристик, зокрема оптичних, таких як ефективний показник заломлення цих пористих композитів, що залежить від структурних параметрів композиції. Для отримання максимально точних результатів використовують числові методи та моделі, що описують відповідний фізичний процес у структурній моделі матеріалу (Farmaga \& Marikutsa, 2015a; Jaworski, Jaworski, Iwaniec \& Lobyr, 2016; Jaworski \& Andrushchak, 2017). Зазвичай це моделі на основі методу скінченних елементів (Jaworski, 2015; Jaworski et al., 2016).

$\mathrm{У}$ цій роботі розвинуто такий числовий метод знаходження ефективного показника заломлення пористих композиційних матеріалів (КМ), що завдяки використанню мікрорівневих коміркових моделей дає змогу досліджувати вплив на нього складних структурних неоднорідностей матеріалу.

Знаходження ефективних характеристик композитів. Визначення залежності характеристик від структурних параметрів КМ здійснюється шляхом гомогенізації. Для цього існують три класи моделей (Jaworski, 2015; Jaworski et al., 2014): емпіричні - базуються на інтерполяції між результатами натурних експериментів; прості структурні - базуються як на відомих аналітичних моделях ефективних полів, так і на числових моделях усереднення, що описують локальний взаємозв'язок матриці композиту та однієї з його компонент; складні мікрорівневі - базуються на числових методах і допускають моделювання неоднорідностей компонент.

Найвідомішою аналітичною моделлю є модель Максвелла-Гарнета, наприклад для знаходження ефективного показника заломлення (Hutchinson et al., 2010; Wang \& Pan, 2008):

$$
n_{e f f}^{2}=n_{m}^{2} \cdot\left(1-\frac{3 \cdot P \cdot\left(n_{m}^{2}-n_{p}^{2}\right)}{2 n_{m}^{2}+n_{p}^{2}+P \cdot\left(n_{m}^{2}-n_{p}^{2}\right)}\right) .
$$

де: $P$ - коефіцієнт пористості, $n_{m}$ - характеристика матриці композиту, $n_{p}$ - характеристика пористої дисперсної фази.

Модель базується на гомогенізації квазістатичного електричного поля в гетерогенному середовищі і може використовуватися для знаходження таких ефективних

\section{Інформація про авторів:}

Яворський Назарій Борисович, канд. техн. наук, асистент. Email: nazariy.jaworski@gmail.com

Андрущак Назарій Анатолійович, канд. техн. наук, асистент. Email: nandrush@gmail.com

Цитування за ДстУ: Яворський Н. Б., Андрущак Н. А. Числовий метод знаходження ефективного показника заломлення пористих композиційних матеріалів на основі мікрорівневих моделей. Науковий вісник НлтУ України. 2018, т. 28, № 6. С. $140-146$.

Citation APA: Jaworski, N. B., \& Andrushchak, N. A. (2018). The numerical method for effective refractive index calculatoin of porous composite materials based on microlevel models. Scientific Bulletin of UNFU, 28(6), 140-146. https://doi.org/10.15421/40280628 
характеристик, як діелектрична проникність, провідність, показник заломлення, коефіцієнт теплопровідності, коефіцієнт дифузії та ін.

Наступною відомою моделлю є модель Брюгермана, що розвинулася у теорію ефективного середовища. Диференціальні рівняння цієї моделі (Hutchinson et al., 2010; Wang \& Pan, 2008) базуються на ітераційному додаванні вкладу кожного компоненту в кінцеву ефективну характеристику, звідки випливає таке відношення:

$$
(1-P) \frac{n_{m}^{2}-n_{e f f}^{2}}{n_{m}^{2}+2 n_{e f f}^{2}}+P \cdot \frac{n_{p}^{2}-n_{e f f}^{2}}{n_{p}^{2}+2 n_{e f f}^{2}}=0 .
$$

Іншою відомою моделлю є модель Друде. 3 диференціальних рівнянь цієї моделі випливає (Hutchinson et al., 2010), що

$$
n_{\text {eff }}^{2}=(1-P) \cdot n_{m}^{2}+P \cdot n_{p}^{2}
$$

Формула (3) також відома як формула Сільберштейна і збігається 3 виразом для знаходження ефективного показника заломлення пористих композитів, що не поглинають випромінювання при застосуванні теорії усереднення об'єму (Volume Averaging Theory) (Hutchinson et al., 2010).

Ще однією 3 найвідоміших є модель паралельного з'єднання провідностей, з якої можна виразити ефективний показник заломлення

$$
n_{\text {eff }}=(1-P) \cdot n_{m}+P \cdot n_{p} .
$$

Аналіз і порівняльні характеристики цих моделей, а також низки інших наведено в багатьох літературних джерелах, зокрема в (Wang \& Pan, 2008).

Найперспективнішими, у плані досліджень, автоматизації та подальшого практичного використання, $€$ клас мікрорівневих моделей, що допускає можливість моделювання неоднорідностей вихідних елементів, та дає змогу максимально адекватно описувати реальні фізичні та просторові структури КМ. Моделі цього класу використовують числові методи розв'язку задач аналізу, такі як метод скінченних елементів (Jaworski, 2015; Jaworski et al., 2014; 2016). Аналіз перебігу фізичних процесів при цьому здійснюється в, так званому, елементарному об'ємі. Результати моделювання фізичних процесів в елементарних об'ємах використовуються для знаходження ефективних характеристик як неявних розв'язків обернених крайових задач (Jaworski, Farmaga \& Lobur, 2012; Jaworski, Farmaga \& Marikutsa, 2012). При цьому немає потреби шукати обернений диференціальний оператор чи використовувати варіаційні методи пошуку необхідних ефективних характеристик, що задовольняють визначальні рівняння при відомих крайових умовах.

Прикладом є метод знаходження ефективного показника заломлення складних композиційних структур на основі вектора Пойтінга, що отримується з числового моделювання поширення поперечних електромагнітних хвиль методом скінченних елементів (Hutchinson et al., 2010). Незважаючи на універсальність та можливість знаходження комплексної компоненти показника заломлення, недоліком цього методу є велика кількість необхідних обчислень порівняно з методом знаходження показника заломлення на основі моделювання електростатичного поля, що представлено у цій роботі. Іншими, більш обмеженими, є мікрорівневі моделі, що використовують метод скінченних різниць, або більш специфічний метод поширення променів.
Побудова структурної моделі пористого композиту. Зазвичай моделювання структури пористого композиту прив'язано до процесу формування пор. 3 іншого боку, моделювання процесу утворення матеріалу є окремою складною задачею, а характерні особливості його кінцевої структури можуть бути наближено описані простішими методами, такими як моделювання циліндричних чи волокнистих включень.

При побудові елементарних об'ємів у даній роботі використовуються коміркові моделі структури (Јаworski \& Andrushchak, 2017; Jaworski, Farmaga \& Marikutsa, 2015a), у вигляді великої кількості регулярних комірок-вокселей, що одночасно представляють собою регулярну скінченно-елементну дискретизацію. Застосовуючи таку формалізацію, елементарний об'єм зручно представляти як тривимірну матрицю скалярних інтенсивностей, умовно в діапазоні від нуля до одиниці. Компоненти композиційного матеріалу визначаються субдіапазонами цих інтенсивностей. Для побудови волокнистих включень, що описують пори композиту, використовують криві Без'є:

1. Визначається кількість необхідних кривих, їх базові координати в елементарному об'ємі, кути повороту довкола базової координати, довжина кривої та діаметр пори.

2. Для кожної кривої задається порядок шляхом визначення випадково зміщених відносно осі $O x$ базисних точок.

3. Кожна крива апроксимується наперед заданою кількістю сегментів однакового розміру між вузлами.

4. Для кожного вузла визначаються його координати відносно елементарного об'єму шляхом застосування афінних перетворень - масштабування відповідно до довжини кривої перенесенням відносно базової координати та застосуванням поворотів довкола базової координати за допомогою матриць обертання.

5. Для кожної комірки елементарного об'єму знаходяться два найближчі вузли кривої, інтенсивність встановлюється пропорційно відстані до ними утвореної прямої.

6. Якщо комірка знаходиться за межами волокна, тобто, якщо найближчими є кінцеві вузли, а проекція комірки на пряму не попадає в кінцевий сегмент, інтенсивність встановлюється пропорційно відстані до кінцевого вузла.

7. Якщо відстань більша за радіус волокна, або інтенсивність комірки є більшою за пропорційну до знайденої відстані, тоді інтенсивність комірки не змінюється.

Кожна пора розміщується в базовій координаті елементарного об'єму, що є вузлом гексагональної тесселяції. Застосування перерізів інтенсивностей елементарних комірок на деякому необхідному рівні дає змогу визначати субдіапазони і таким способом контролювати середній розмір пори, або утворювати багатошарові трубкоподібні структури (Jaworski \& Andrushchak, 2017).

Задача побудови структури підлягає декомпозиції за даними і може бути досить просто реалізована на SIMD apхітектурах обчислювальних пристроїв за допомогою технологій паралельних і розподілених обчислень, наприклад технологію OpenCL (Jaworski, Farmaga \& Marikutsa, 2015b).

Використання кривих Без'є дає змогу моделювати пори $з$ врахуванням наноструктурних неоднорідностей. Завдяки регулярній структурі отриману мікрорівневу модель можна використовувати безпосередньо як скінченно-елементну дискретизацію. 
Синтез ефективного показника заломлення. Обмежимося розглядом діелектриків, якими є пористі композиційні матеріали, що застосовуються в оптиці. Можна припустити, що магнітне поле є відсутнім, а довжина хвилі електромагнітного поля $\lambda$ =const. Тоді 3 відомої системи рівнянь Максвелла можна вивести еліптичне рівняння для потенціалу електростатичного поля

$$
\varepsilon \nabla^{2} U=0
$$

де: $\varepsilon$ - діелектрична проникність, $U$ - потенціал. Розглянемо модель однорідного елементарного об'єму композиту в формі куба, діелектричну проникність можна знайти як

$$
\varepsilon=\frac{d \cdot \rho}{\Gamma_{\rho}\left(U_{\Gamma_{\rho}}-U_{\infty}\right)},
$$

де: $\Gamma_{\rho}-$ площа поверхні елементарного об'єму, де задано потік густини заряду $\rho$; $U_{\infty}-$ потенціал на протилежній стороні; $d$ - довжина елементарного об'єму. Запишемо крайову задачу:

$$
\begin{gathered}
\mathcal{L}_{\Omega}(U(\mathbf{x}))=\varepsilon \nabla^{2} U(\mathbf{x})=0, \quad \mathbf{x} \in \Omega, \\
\left.\mathcal{C}_{\Gamma_{q}}(U(\mathbf{x}))\right|_{\Gamma_{q}}=\left.\frac{\partial U}{\partial \mathbf{n}}\right|_{\Gamma_{q}}=\rho, \quad \mathbf{n} \perp \Gamma_{\rho}, \\
\left.\mathcal{C}_{\Gamma_{U}}(U(\mathbf{x}))\right|_{\Gamma_{U}}=\left.U\right|_{\Gamma_{U}}=U_{\infty} .
\end{gathered}
$$

Треба зауважити, що потенціальне поле повинно бути неперервним при переході між можливими неоднорідними фазами матеріалу, тобто необхідно вказати, так звану, крайову умову четвертого роду, що також називають ідеальним контактом. Проте при подальшому числовому розв'язку задачі методом скінченних елементів, ця умова автоматично задовольняється вимогою узгодженості скінченно-елементного базису, тому явно не вказується.

Для розв'язку задачі використовуємо метод скінченних елементів у формулюванні зважених нев'язок (Јаworski, 2015; Jaworski, Tesliuk \& Lytvynova, 2016). Наближений пробний розв'язок шукається у вигляді

$$
U(\mathbf{x}) \approx \tilde{U}(\mathbf{x})=\sum_{j=1}^{M} U_{j} \varphi_{j}(\mathbf{x}),
$$

де: $U_{j}-$ невідомий потенціал у комірках елементарного об'єму; $\varphi_{j}$ - деяка проста поліноміальна базисна функція. Підставивши пробний розв'язок у крайову задачу, отримаємо відмінні від нуля нев'язки:

$$
R^{\Omega}(\mathbf{x}) \neq 0, \quad R^{\Gamma_{\rho}}(\mathbf{x}) \neq \rho, \quad R^{\Gamma_{U}}(\mathbf{x})=U_{\infty} .
$$

Зауважимо, що $R^{\Gamma_{U}}$ задовольняється точно.

Найкращою апроксимацією точного розв'язку $U(\mathbf{x}) \in \mathcal{H}^{\infty}(\Omega)$ завжди є ортогональна проекція $\tilde{U}(\mathbf{x})$ у підпростір $C^{1} \subset \mathcal{H}^{\infty}(\Omega)$ що визначається базисними функціями $\varphi$ :

$$
\left\langle R^{\Omega}(\mathbf{x}), \varphi_{i}^{\Omega}(\mathbf{x})\right\rangle+\left\langle R^{\Gamma_{\rho}}(\mathbf{x}), \varphi_{i}^{\Gamma_{\rho}}(\mathbf{x})\right\rangle=0, i=\overline{1, M}, \varphi_{i}^{\Omega}=-\varphi_{i}^{\Gamma_{\rho}} .
$$

або

$$
\begin{aligned}
& \iiint_{\Omega} \varphi_{i}^{\Omega}(\mathbf{x})\left[\sum_{j=1}^{M} U_{j} \mathcal{L}\left(\varphi_{j}(\mathbf{x})\right)\right] d \Omega+ \\
& { }^{\prime}(\mathbf{x})\left[\sum_{j=1}^{M} U_{j} l\left(\varphi_{j}(\mathbf{x})\right)-\rho\right] d \Gamma_{\rho}=0, i=\overline{1, M},
\end{aligned}
$$

Гладкість $C^{1}$ пробного розв'язку є мінімально допустимою, оскільки в початковому рівнянні присутні похідні максимум другого порядку. Отриманий вираз можна переписати у слабкій формі і в такий спосібослабити вимоги до гладкості базисних функцій $\left(\varphi \in C^{1} \Rightarrow \varphi \in C^{0}\right)$. Наприклад, використовуючи правило інтегрування за частинами та теорему про дивергенцію, в останній вираз можна включити крайові умови Неймана, що є для нього природними $\left(\varphi_{i}^{\Omega}=-\varphi_{i}^{\Gamma_{\rho}}\right)$ :

$$
\left[\iint_{\Omega}\left[\frac{\partial \varphi_{i}}{\partial x} \frac{\partial \varphi_{j}}{\partial x}+\frac{\partial \varphi_{i}}{\partial y} \frac{\partial \varphi_{j}}{\partial y}+\frac{\partial \varphi_{i}}{\partial z} \frac{\partial \varphi_{j}}{\partial z}\right] d x d y d z\right] U_{j}=-\iint_{\Gamma_{\rho}} \rho \varphi_{i} d \Gamma_{\rho} .
$$

Змінимо позначення на більш звичні матрицю жорсткості та вектор навантажень $[\mathbf{K}]\{\mathbf{u}\}=\{\mathbf{f}\}$ (квадратні дужки позначають матрицю, фігурні - вектор).

Розіб'ємо елементарний об'єм $\Omega \subset \mathbf{R}^{3}$ на симплекс елементи (тетраедри) $\Omega_{i} \subset \Omega \subset \mathbf{R}^{3}, i=1,2, \ldots, P$. Використання симплекс елементів $є$ допустимим, оскільки такий базис $\epsilon C^{0}$ гладким та легко узгоджується з сусідніми (потенціал буде неперервний при переході між елементами). Для цього використовуємо простий шаблонний метод, при якому кожні вісім сусідніх комірки елементарного об'єму утворюють куб, що розбивається на шість тетраедрів. Задача зводиться до знаходження всіх "локальних" матриць жорсткості $[\mathbf{K}]_{i}$ та векторів $\{\mathbf{f}\}_{i}$. Для лінійного симплекс елементу базисні функції форми є його барицентричними координатами:

$$
\begin{gathered}
\varepsilon_{i} \sum_{j=1}^{4} U_{i, j} N_{i, j}(\mathbf{x})= \\
=\varepsilon_{i}\left[N_{i, 1} N_{i, 2} N_{i, 3} N_{i, 4}\right] \cdot\left\{U_{i, 1} U_{i, 2} U_{i, 3} U_{i, 4}\right\}^{\mathbf{T}}=[\mathbf{N}]_{i}\left\{\mathbf{u}_{i},\right. \\
{[\mathbf{N}]=\left[\begin{array}{llll}
1 & x & y & z
\end{array}\right]\left[\begin{array}{llll}
1 & x_{1} & y_{1} & z_{1} \\
1 & x_{2} & y_{2} & z_{2} \\
1 & x_{3} & y_{3} & z_{3} \\
1 & x_{4} & y_{4} & z_{4}
\end{array}\right]^{-1}=} \\
=\left[\begin{array}{llll}
1 & x & y & z
\end{array}\right]\left[\begin{array}{llll}
a_{1} & a_{2} & a_{3} & a_{4} \\
b_{1} & b_{2} & b_{3} & b_{4} \\
c_{1} & c_{2} & c_{3} & c_{4} \\
d_{1} & d_{2} & d_{3} & d_{4}
\end{array}\right]
\end{gathered}
$$

де$$
\left[\begin{array}{llll}
c_{1} & c_{2} & c_{3} & c_{4} \\
d_{1} & d_{2} & d_{3} & d_{4}
\end{array}\right]
$$

Оскільки кожна зі сторін тетраедра є трикутником двовимірним симплексом, можна визначити локальні вектори навантажень. Наприклад, для перших трьох вузлів тетраедра:

$$
\begin{aligned}
& \left\{\mathbf{f}_{i}=-\iint_{\Gamma_{\rho}}[\mathbf{N}]^{\mathbf{T}} \rho d \Gamma_{\rho}=-\rho \int_{\Gamma_{\rho}}\left\{\begin{array}{c}
N_{1} \\
N_{2} \\
N_{3} \\
0
\end{array}\right\} d \Gamma_{\rho}=\right. \\
& \left.=-\rho \int_{0}^{1} \int_{0}^{1-N_{1} 1-N_{1}-N_{2}} \int_{0}^{N_{1}} \begin{array}{c}
N_{2} \\
N_{3} \\
0
\end{array}\right\}\left[\mathbf{J a c}_{\mathbf{N}} \mathbf{r}\right] \mid d N_{3} d N_{2} d N_{1}=\rho \frac{\left(\Gamma_{\rho}\right)_{i}}{3}, i=\overline{1, M}
\end{aligned}
$$

Якщо скінченний елемент не знаходиться на границі, де визначені крайові умови, його вектор навантаження залишиться рівним нулю - локальна крайова задача $\epsilon$ некоректно поставленою (плаваючою) і не може бути розв'язана без розгляду сусідніх. Для врахування крайової умови Діріхле достатньо модифікувати локальну систему рівнянь, приймаючи граничний вузловий потенціал рівним заданому $U_{\infty}$, тобто точно задовольнити нев'язку $R^{\Gamma_{U}}$.

Записавши слабку форму задачі, можна виразити матричну слабку форму її оператора

$$
[\mathcal{L}]=\nabla(.)=\left[\begin{array}{lll}
\frac{\partial}{\partial x} & \frac{\partial}{\partial y} & \frac{\partial}{\partial z}
\end{array}\right]^{\mathbf{T}}
$$

Внаслідок цього кожна локальна задача може бути записана як: 


$$
\begin{gathered}
{\left[\iint_{\Omega_{i}}\left([\mathcal{L}][\mathbf{N}]_{i}\right)^{\mathbf{T}}[\mathbf{D}]_{i}\left([\mathcal{L}][\mathbf{N}]_{i}\right) d x d y d z\right]\{\mathbf{u}\}_{i}=\{\mathbf{f}\}_{i},} \\
{[\mathbf{D}]_{i}=\left[\begin{array}{ccc}
\varepsilon_{i} & 0 & 0 \\
0 & \varepsilon_{i} & 0 \\
0 & 0 & \varepsilon_{i}
\end{array}\right] .}
\end{gathered}
$$

Значення матриць $[\mathbf{D}]_{i}$ залежать від того, в якій підобласті $\Omega_{p}$ розміщений скінченний елемент. Вираз $\left([\mathcal{L}][\mathbf{N}]_{i}\right)$ дає $3 \times 4$ матрицю, що містить тільки константи:

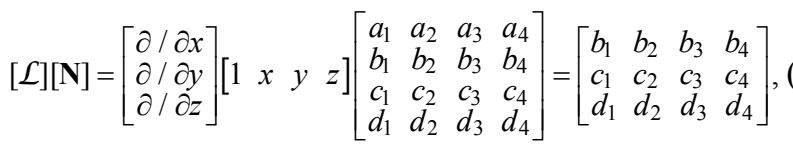

звідки

$$
[\mathbf{K}]_{i}\{\mathbf{u}\}_{i}=\{\mathbf{f}\}_{i}, \quad[\mathbf{K}]_{i}=\left([\mathcal{L}][\mathbf{N}]_{i}\right)^{\mathbf{T}}[\mathbf{D}]_{i}\left([\mathcal{L}][\mathbf{N}]_{i}\right) \Omega_{i} .
$$

Після знаходження всіх локальних матриць жорсткості та векторів навантаження, за допомогою процедури ансамблювання, їх потрібно зібрати в глобальну СЛАР, розв'язок якої є наближеним розв'язком вихідної крайової задачі. Розв'язок зручно шукати наближено 3 допомогою стабілізованого (стійкого до обчислювальних помилок) методу спряжених градієнтів 3 допомогою готових OpenCL реалізацій.

Вираз питомого опору для багатошарового КМ, з гетерогенними шарами, що лежать паралельно до потоку визначається як

$$
\frac{1}{R_{U}}=\sum_{i=1}^{n} \frac{1}{R_{U i}} .
$$

Після розв'язку крайової задачі стають відомі значення потенціалів у вузлах дискретних елементів, отже, стають відомі потенціали на протилежних поверхнях КМ. Неоднорідні потенціали поверхні, утворені при заданому потоці, описує набір вузлів скінченних елементів, при цьому на протилежній поверхні потенціали є відомими і рівномірними, кожен елемент поверхні відображатиме питомий опір $R_{U i}$, значення якого, у випадку симплекс елементів, виражається як

$$
\begin{gathered}
R_{U i}=\frac{(\Delta U)_{i}}{\rho}=\frac{1}{\left(\Gamma_{\rho}\right)_{i} \cdot \rho} \iint_{\Gamma_{\rho}}\left(\left(U_{\Gamma_{\rho}}\right)_{i, j}-U_{\infty}\right) d\left(\Gamma_{\rho}\right)_{i}= \\
=\frac{1}{3\left(\Gamma_{\rho}\right)_{i} \cdot \rho} \sum_{j=1}^{3}\left(\left(U_{\Gamma_{\rho}}\right)_{i, j}-U_{\infty}\right),
\end{gathered}
$$

де: $n=3$ - кількість вузлів елементу поверхні; $\left(\Gamma_{\rho}\right)_{i}-$ площа елементу поверхні, $\rho$ - відомий потік через $\Gamma_{\rho}$ (умова Неймана); $\left(U_{\Gamma_{\rho}}\right)_{i, j}-$ значення потенціалу в і-му вузлі $j$-го елемента на поверхні; $U_{\infty}$ - відомий потенціал на протилежній поверхні (умова Діріхле). Тому

$$
\frac{1}{R_{U}}=\sum_{i=1}^{P_{\Gamma}} \frac{1}{R_{U i}}=\rho \cdot \sum_{i=1}^{P_{\Gamma}} \frac{3\left(\Gamma_{\rho}\right)_{i}}{\sum_{j=1}^{3}\left(\left(U_{\Gamma_{\rho}}\right)_{i, j}-U_{\infty}\right)},
$$

де $P_{\Gamma_{\rho}}-$ кількість елементів поверхні КМ. Різниця потенціалів між поверхнями КМ виражається як

$$
\Delta U=\left(\sum_{i=1}^{P_{\Gamma_{\rho}}} \frac{3\left(\Gamma_{\rho}\right)_{i}}{\sum_{j=1}^{3}\left(\left(U_{\Gamma_{\rho}}\right)_{i, j}-U_{\infty}\right)}\right)^{-1} .
$$

Ефективна діелектрична проникність визначається як

$$
\varepsilon_{e f f}=\frac{d \cdot \rho}{\Gamma_{\rho} \cdot \Delta U}=\frac{d \cdot \rho}{\iint_{\Gamma_{\rho}}\left(U_{\Gamma_{\rho}}-U_{\infty}\right) d \Gamma_{\rho}}=\frac{d \cdot \rho}{\Gamma_{\rho}} \sum_{j=1}^{P_{\Gamma}} \frac{3\left(\Gamma_{\rho}\right)_{j}}{\sum_{i=1}^{3}\left(U_{\rho i, j}-U_{\infty}\right)} .
$$

Для діелектриків показник заломлення середовища можна виразити як $n^{2}=\varepsilon$, звідки отримаємо вираз для ефективного показника заломлення

$$
n_{e f f}^{2}=\frac{d \cdot \rho}{\iint_{\Gamma_{\rho}}\left(U_{\Gamma_{\rho}}-U_{\infty}\right) d \Gamma_{\rho}}=\frac{d \cdot \rho}{\Gamma_{\rho}} \sum_{j=1}^{P_{\Gamma_{\rho}}} \frac{3\left(\Gamma_{\rho}\right)_{j}}{\sum_{i=1}^{3}\left(U_{\rho i, j}-U_{\infty}\right)} .
$$

Оскільки вхідними параметрами є не діелектричні проникності, а показники заломлення компонент композиційного матеріалу, необхідно також модифікувати матриці жорсткості

$$
[\mathbf{D}]_{i}=\left[\begin{array}{ccc}
n_{i}^{2} & 0 & 0 \\
0 & n_{i}^{2} & 0 \\
0 & 0 & n_{i}^{2}
\end{array}\right] .
$$

Результати моделювання та їх оцінка. Описаний в цій роботі метод знаходження ефективного показника заломлення пористих композиційних структур був програмно реалізований алгоритмічною мовою $\mathrm{C}++113$ використанням OpenCL версії 1.2, та Qt SDK версії 5.4.1. Робоча операційна система Windows 7 Ultimate х64. Програма зібрана під х64 за допомогою компілятоpa MinGW версії 4.9.2. Моделювання проводилися на персональному комп'ютері пересічної комплектації. Зокрема OpenCL GPU: "Cedar (AMD Radeon HD 6300M Series)", AMD OpenCL SDK 2.9.1 driver 1445.5 (VM), $2 \times 12$ computing units $0.750 \mathrm{GHz}$, (робоча група $4 \times 4 \times 4$ ). Параметри побудованої моделі структури матеріалу:

- елементарний об'єм з $128^{3}$ комірками в еквіваленті $9,1 \cdot 10^{-7} \mathrm{M}^{3}$;

- матриця з показником заломлення $n=4$;

- фаза армування 3 показником заломлення $n=1$ - пористі включення що апроксимовані кривими Без'є 4-го порядку по 5 лінійних відрізків на криву з міжпоровою відстанню $1,3 \cdot 10^{-7} \mathrm{M}$, максимальним діаметром пор $10^{-7} \mathrm{M}$, довжиною пор $9,1 \cdot 10^{-7}$ м, розкид діаметра в діапазоні $20 \%$, відхилення кожного вузла кривої від лінійної осі в діапазоні 1 \% від довжини;

- зміна пористості відбувалася за рахунок застосування перерізу інтенсивностей комірок мікрорівневої моделі композиту, що еквівалентно зміні діаметра пор.

На рис. 1 зображено приклад утворених потенціальних полів при проходженні потоку вздовж та впоперек пористої фази композиту. Верифікація проводилася порівнянням 3 аналітичними моделями (Wang \& Pan, 2008; Hutchinson et al., 2010). Результати показано на рис. 2, з яких видно узгодження з моделлю Друде.

Згідно $з$ теорією (Jaworski, Tesliuk \& Lytvynova, 2016), необхідними і достатніми умовами збіжності моделі на основі методу скінченних елементів є умови лінійної незалежності, повноти, допустимості та узгодженості обраних базисних функцій. Реалізованими програмно є скінченні симплекс-елементи, які описуються лінійними функціями координат, тобто поліномами першого порядку, що є виразами відповідних барицентричних координат, які лінійно незалежні. Використання симплекс-елементів є частковим випадком використання сімейства поліноміальних Лагранжевих елементів. Згідно з відомою апроксимаційною теоремою Стоуна-Вейєрштрасса, обрана система базисних функцій $є$ повною. Присутні у визначальних рівняннях зважених нев'язок диференціальні оператори містять похідні що- 
найвище першого порядку, що відповідає $C^{1}$ гладким розв'язкам. Це означає, що допустимими для апроксимації є сімейства $C^{0}$ гладких базисних функцій, якими $\epsilon$ функції форми симплекс-елементів. Оскільки симплекс-елементи визначаються розміщенням вузлів дис- кретизації, сусідні елементи мають спільні вузли. Відповідні барицентричні координати вздовж спільної границі будуть однаковими, що відповідає умові узгодженості скінченно-елементного базису. Отже, теоретично модельні обчислення є збіжними.
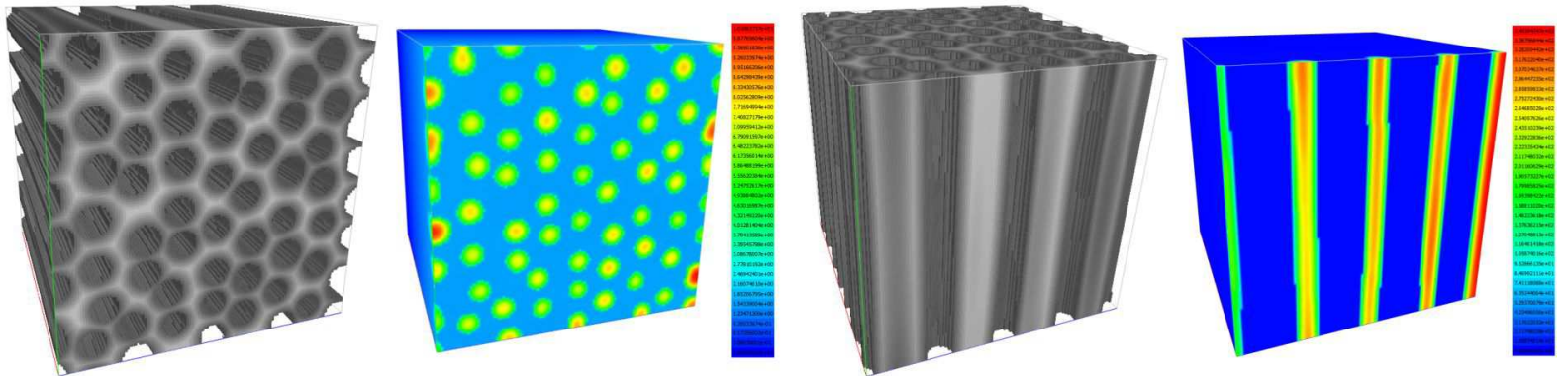

Рис. 1. Приклад знайдених потенціальних полів у елементарному об'ємі композиційного матеріалу пористої структури
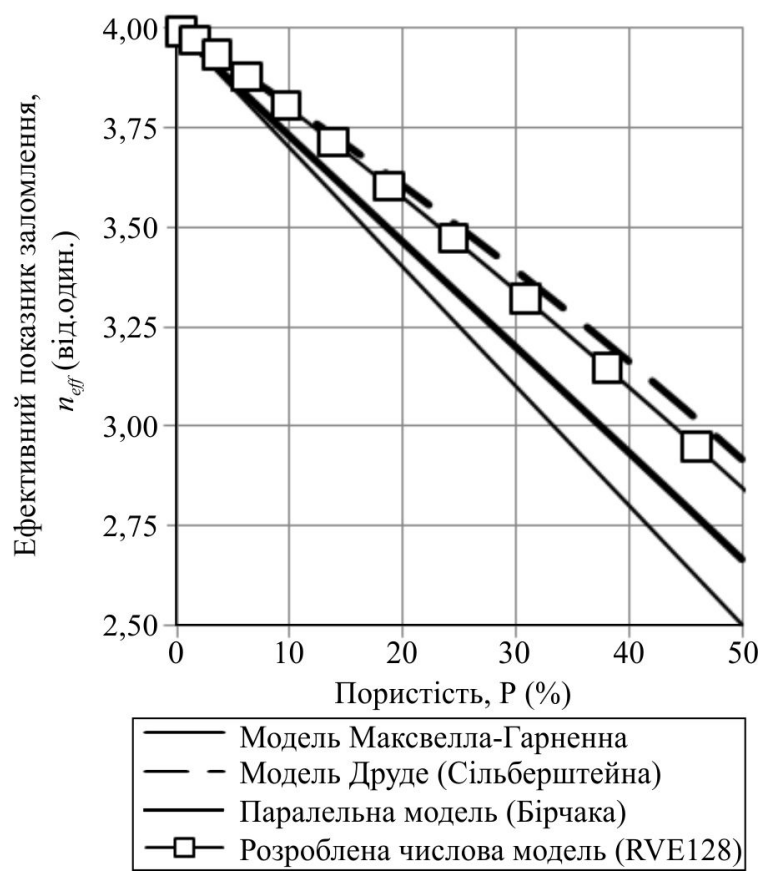

Рис. 2. Порівняння результатів знаходження ефективного показника заломлення пористого композиційного матеріалу за допомогою розробленої числової моделі з результатами відомих аналітичних моделей

Для будь-якої функції $u \in \mathcal{H}^{p}(\Omega)$ похибка інтерполяції скінченними елементами виражається як

$$
\begin{gathered}
\left\|u-\tilde{u}_{I}\right\|_{\mathcal{H}^{s}(\Omega)} \leq C h^{k+1-s}\|u\|_{\mathcal{H}^{k+1}(\Omega)}, \quad s \geq 2 p-(k+1), \\
\left\|u-\tilde{u}_{I}\right\|_{\mathcal{H}^{s}(\Omega)} \leq C h^{2(k+1-p)}\|u\|_{\mathcal{H}^{k+1}(\Omega)}, \quad s \leq 2 p-(k+1),
\end{gathered}
$$

де: $\tilde{u}_{I}-$ наближений розв'язок, що має інтерполяційну (сіткову) природу; $h$ - характерний розмір елементів; $k$ - порядок функцій форми елементів; $s$ - порядок розглянутої похідної, тобто $s=0,1, \ldots, k$. Константа $C$ залежить від самого об'єкта моделювання і не залежить від характерних розмірів елементів. Тобто похибка апроксимації оцінюється у вигляді норми, що описує верхню границю. У цьому випадку це означає, що при згущенні дискретизації отримане потенціальне поле у вузлах дискретизації та в сукупності буде прямувати до точного розв'язку знизу - на кожній ітерації потенціали повинні зростати на деяке значення, що постійно зменшуватиметься.

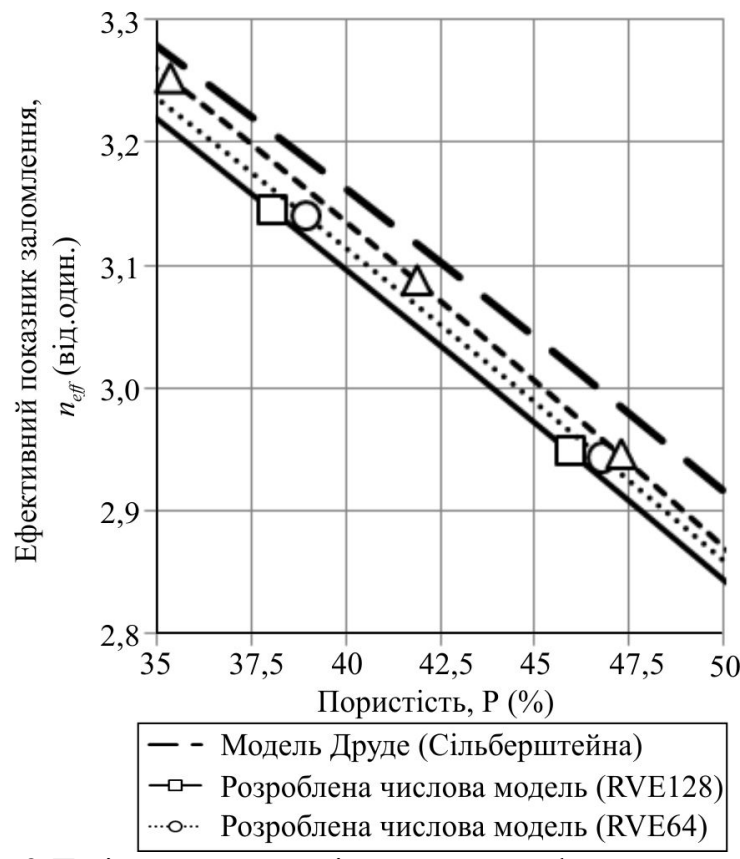

Рис. 3. Порівняння результатів знаходження ефективного показника заломлення пористого композиційного матеріалу за допомогою розробленої числової моделі при згущенні дискретизації

Для перевірки останнього твердження було проведено низку числових експериментів 3 поступовим згущенням дискретизації для елементарних об'ємів $332^{3}, 64^{3}$ та $128^{3}$ комірками. 3 отриманих результатів видно (рис. 3), що на кожній ітерації згущення дискретизації, потенціальне поле, як і очікувалося, прямує до точного розв'язку знизу, а відповідний йому знайдений ефективний показник заломлення - зверху. Отже, програмно реалізована модель відповідає умові збіжності і використовуючи густу дискретизацію, за допомогою неї, можна знайти достатньо точний розв'язок. Спираючись на оцінку верхньої границі похибки апроксимації методу скінченних елементів, отримані результати також свідчать про більшу точність результатів порівняно з аналітичною моделлю Друде.

Висновки. У цій роботі на основі використання мікрорівневої коміркової моделі структури, методу генерування випадкових волокнистих включень 3 допомогою кривих Без'є, числової скінченно-елементної моделі електростатичних процесів та методу електростатичних аналогій розвинено метод знаходження ефективного показника заломлення пористих композиційних матеріалів, що дає змогу в рамках однотипної моделі розгля- 
дати складні структурні неоднорідності матеріалу, безпосередньо використовувати іiі як регулярну дискретизацію і цим самим зменшити кількість необхідних обчислень та синтезувати ефективний показник заломлення пористого композиту на основі результатів числового моделювання електростатичного поля, реалізація якого $є$ простішою та потребує меншої кількості обчислень, ніж в аналогічних методах. Спираючись на оцінку верхньої границі похибки апроксимації використаного методу скінченних елементів, отримані результати також свідчать про більшу точність порівняно $з$ аналітичною моделлю.

Подяка. Цю роботу виконано за підтримки Міністерства освіти та науки України в рамках Гранту молодих учених ДБ/Нанокомпозит (номер державної реєстрації 0116U004412).

\section{Перелік використаних джерел}

Andrushchak, N., Jaworski, N., \& Lobur, M. (2018). Improvement of the Numerical Method for Effective Refractive Index Calculation of Porous Composite Materials Using Microlevel Models. Acta Physica Polonica A., 133(1), 164-166. http://doi.org/10.12693/APhysPolA.133.164

Hutchinson, N., et al. (2010). Effective optical properties of highly ordered mesoporous thin films. Thin Solid Films, 518(8), 21412146. https://doi.org/10.1016/i.tsf.2009.08.048

Jaworski, N. (2015). Effective Thermal Characteristics Synthesis Microlevel Models in the Problems of Composite Materials Optimal Design. ECONTECHMOD, 4(2), 3-12.

Jaworski, N. B., Farmaga, I. V., \& Marikutsa, U. B. (2015a). Building the micro-level composite materials structure models in the problems of their optimal design. Scientific Bulletin of UNFU, 25(8), 359-366.

Jaworski, N. B., Farmaga, I. V., \& Marikutsa, U. B. (2015b). Metod pobudovy vypadkovykh perekhidnykh shariv ta yoho zastosuvannia u multymasshtabnomu modeliuvanni struktur heterohennykh seredovyshch za dopomohoiu tekhnolohii OpenCL.
Visnyk Natsionalnoho universytetu "Lvivska politekhnika", Seriia: Kompiuterni nauky ta informatsiini tekhnolohii, 826, 385-394.

Jaworski, N. B., Tesliuk, V. M., \& Lytvynova, Ye. I. (2016). Kompiuterni metody $v$ inzhenerii mikroelektromekhanichnykh system. Lviv: Vydavnytstvo Lvivskoi politekhniky. 304 p.

Jaworski, N., et al. (2014). Thermal Analysis Methods for Design of Composite Materials with Complex Structure. ECS Transactions, $59(1), 513-523$.

Jaworski, N., et al. (2016). Diamond-Based Metal Matrix Composite Effective Heat Conduction Coefficient Synthesis Microlevel Model Verification. MEMSTECH'2016, (pp. 25-27).

Jaworski, N. Farmaga, I., \& Lobur, M. (2012). Finding Effective Thermal Characteristics of Composite Materials Based on the Analysis of Thermal Conductivities. Visnyk NU "Lvivska politekhnika": Kompiuterni systemy proektuvannia. teoriia $i$ praktyka, 747, 59-65.

Jaworski, N., \& Andrushchak, N. (2017). A method of nanoporous anodic aluminum oxide structure modeling based on bezier curves generation. CADSM 2017, (pp. 63-66).

Jaworski, N., \& Andrushchak, N. (2017). A numerical model of light propagation in porous composite structures. OMEE 2017, (pp. 92-94).

Jaworski, N., Farmaga, I., \& Marikutsa, U. (2012). Rozroblennia dyskretnoi modeli znakhodzhennia efektyvnykh teplofizychnykh kharakterystyk kompozytnykh materialiv zi skladnoiu strukturoiu. Visnyk NU "Lvivska politekhnika", Seriia: Kompiuterni nauky ta informatsiini tekhnolohii, 744, 152-158.

Jaworski, N., Iwaniec, M., \& Lobyr, M. (2016). Composite Materials Microlevel Structure Models Visualization Distributed Subsystem based on WebGL. MEMSTECH 2016, (pp. 22-24).

Jaworski, N., Lobyr, M., Matviykiv, O., Farmaga, I., \& Marikutsa, U. (2017). Synthesis of effective thermal characteristics of anodic alumina by the microlevel cellular composite materials model. MICROTHERM 2017, (pp.26-28.

Wang, M., \& Pan, N. (2008). Predictions of effective physical properties of complex multiphase materials. International Journal Materials Science and Engineering, 63, 1-30. https://doi.org/10.1016/j.proeng.2017.09.909

Н. Б. Яворский, Н. А. Андрущак
Национальный университет "Львовская политехника", г. Львов, Украина

\section{ЧИСЛЕННЫЙ МЕТОД НАХОЖДЕНИЯ ЭФФЕКТИВНОГО ПОКАЗАТЕЛЯ ПРЕЛОМЛЕНИЯ ПОРИСТЫХ КОМПОЗИЦИОННЫХ МАТЕРИАЛОВ НА ОСНОВЕ МИКРОУРОВНЕВЫХ МОДЕЛЕЙ}

Рассмотрено применение разработанного численного метода нахождения эффективного показателя преломления для случая пористых нанокомпозитов. На основе использования микроуровневых ячеистых моделей структуры, метода генерирования случайных волокнистых включений с помощью кривых Безье и микроуровневых ячеистых моделей структуры развит численный метод нахождения эффективного показателя преломления пористых композитов, который позволяет в рамках однотипной модели рассматривать сложные структурные неоднородности материала и синтезировать соответствующий показатель преломления на основе численного моделирования электростатического поля. Такая реализация является простой и требует меньшего количества вычислений и ресурсов по сравнению с аналитическими методами. Благодаря регулярной структуре полученную микроуровневую модель можно использовать непосредственно как конечно-элементную дискретизацию, так как использование кривых Безье дает возможность моделировать время с учетом наноструктурных неоднородностей. Предложенный метод был проверен путем сравнения с существующими аналитическими моделями нахождения эффективного показателя преломления, такими как: Максвелла-Гарнета, моделью Брюгемана и моделью Друде (Сильберштейна). Опираясь на оценку верхней границы погрешности аппроксимации использованного метода конечных элементов, полученные результаты свидетельствуют о большей точности по сравнению с аналитической моделью Друде (Сильберштейна).

Ключевые слова: композиционные материалы; микроуровневые модели; численное моделирование.

N. B. Jaworski, N. A. Andrushchak Lviv Polytechnic National University, Lviv, Ukraine

\section{THE NUMERICAL METHOD FOR EFFECTIVE REFRACTIVE INDEX CALCULATOIN OF POROUS COMPOSITE MATERIALS BASED ON MICROLEVEL MODELS}

The application of the developed numerical method for finding an effective refractive index of porous nanocomposites is shown. The numerical method of finding an effective refractive index of porous composites is developed on the basis of the use of the microlevel cellular structure model, the method of generation of random fibrous inclusions with the help of Bezier curves and micro-level cellular models. The cellular models are used in this paper for generation of porous composites structural models. They describe composite structure by representative volume elements that contains big amount of regular voxel cells that can be simultaneously 
used as finite element discretization. Voxel cells contain scalar intensities in diapason from 0 to 1 . This enables the description of nanostructural heterogeneity of material within a model, and its direct use as a regular finite-element discretization. This method allows considering complex structural inhomogeneities of the material within the framework of a similar model and to synthesize the corresponding refractive index on the basis of numerical simulation of the electrostatic field. The method of finding an effective index of refraction of porous composite structures described in this paper was programmed in $\mathrm{C}++11$ algorithmic language using OpenCL version 1.2 and Qt SDK version 5.4.1. The proposed implementation is simpler and requires less computation poser and resources comparing to similar analytical methods. Due to the regular structure, the obtained micro-level model can be used directly as finite-element sampling, since the use of Bezier curves enables the pores to be modeled taking into account nanostructural heterogeneities. The proposed method was tested by comparing with existing analytical models for finding an effective refractive index, such as Maxwell-Garnett model, Bruggeman model and Drude (Silberstein) model. Based on the estimation of the upper bound of the finite element method approximation error, the obtained results indicate greater accuracy compared to the Drude (Silberstein) analytical model.

Keywords: composite materials; microlevel models; numerical simulation. 